\title{
Procedural memory: computer learning in control subjects and in Parkinson's disease patients
}

\author{
C. Thomas-Antérion ${ }^{1}$, B. Laurent ${ }^{1}$, N. Foyatier-Michel', S. Laporte ${ }^{2}$ and D. Michel ${ }^{1}$ \\ ${ }^{1}$ Service de Neurologie and ${ }^{2}$ Service de Médecine Interne et de Thérapeutique, Hôpital de \\ Bellevue, Boulevard Pasteur, Saint-Etienne, France \\ Correspondence to: C. Thomas-Antérion, Service de Neurologie, C.H.U. de Saint-Etienne, \\ Hôpital de Bellevue, 42055 Sant-Etienne Cedex 2, France
}

\begin{abstract}
We used perceptual motor tasks involving the learning of mouse control by looking at a Macintosh computer screen. We studied 90 control subjects aged between sixteen and seventy-five years. There was a significant time difference between the scales of age but improvement was the same for all subjects. We also studied 24 patients with Parkinson's disease (PD). We observed an influence of age and also of educational levels. The PD patients had difficulties of learning in all tests but they did not show differences in time when compared to the control group in the first learning session (Student's $t$-test). They learned two or four and a half times less well than the control group. In the first test, they had some difficulty in initiating the procedure and learned eight times less well than the control group. Performances seemed to be heterogeneous: patients with only tremor (seven) and patients without treatment (five) performed better than others but learned less. Success in procedural tasks for the PD group seemed to depend on the capacity to initiate the response and not on the development of an accurate strategy. Many questions still remain unanswered, and we have to study different kinds of implicit memory tasks to differentiate performance in control and basal ganglia groups.
\end{abstract}

Keywords: Parkinson's disease - Memory - Learning - Visuomotor skills

\section{INTRODUCTION}

Many dissociations of memory processes have been described with different anatomical systems subserving distinct memory functions: the most usual distinctions are between episodic and semantic memory (Parkin, 1982; Tulving, 1982) and between procedural and declarative memory (Cohen and Squire, 1980). The explicit or implicit categorization was employed by Schacter (1987) with a very similar meaning. Implicit memory encompasses a variety of distinct learning processes such as classical conditioning, priming and skill learning.

As described by Cohen and Squire (1980) and later Tulving (1985), procedural memory is defined as the ability to acquire a motor skill or a cognitive routine by experience. Representing a 'knowing how' the learning can be expressed implicitly by analyzing the behavior and the performance facilitation without conscious recollection from a previous learning episode (Schacter, 1987). Subjects have not to learn or remember a task but only to do it. In contrast explicit memory necessitates a conscious recollection of learning. The alterations and dissociations of explicit and implicit memory vary in neurological patients and in normal people during aging (El-Awar et al., 1987; Bondi and Kaszniak, 1991).

Amnesic subjects can acquire and retain a variety of motor, perceptual and cognitive skills (for example maze learning, pursuit-rotor, mirror reading or writing) despite poor explicit memory for the learning episodes. They are able to acquire these new skills despite their inability to recall the context of the experience (Corkin, 1968; Milner et al., 1968; Brooks and Baddeley, 1976; Serdaru and Lhermitte, 1981; Cohen, 1984; Martone et al., 1984; Knopman and Nissen, 1987). They can also acquire cognitive procedures such as the Tower of Hanoï, the Tower of Toronto or the Tower of London (Parkin, 1982; Warrington and Weiskrantz, 1982; Squire and Cohen, 1984). Glisky et al. (1986) and Glinsky and Schacter (1989) showed that a severely amnesic patient can acquire knowledge and interact with a microcomputer after several training sessions with vanishing cues.

In diseases of the basal ganglia implicit memory could be impaired in isolation with preservation of explicit learning in comparison to the classical dissociation of neurological amnesia. Further, comparisons of 
patients with different degenerative brain diseases show dissociations on various implicit memory tasks such as skill learning or priming. Heindel et al (1989) compared Huntington's disease (HD) and Alzheimer's disease (AD) patients on two implicit memory tests: HD patients were impaired on a pursuit-rotor learning task but performed normally on a priming task, while $\mathrm{AD}$ patients displayed the opposite pattern.

Many works since Saint Cyr et al. (1988), have shown that Parkinson's disease (PD) patients are selectively impaired on procedural learning tasks such as the Tower of Toronto. Morris et al. (1988) used a computerized version of the Tower of London task to show that PD patients solved the puzzle with the same number of moves as control subjects, but were slower to initiate the first move and had difficulty in sequencing the subsequent moves. Frith et al., (1986) also showed the difficulties of PD patients in initiating movement on a pursuit-rotor learning task. Harrington and Haaland (1991) showed that PD patients were impaired in their ability to initiate and select movements influenced by both sequence length and complexity. In contrast, Bondi and Kaszniak (1991) showed normal performance for PD patients on a pursuit-rotor tracking and on a mirror reading task.

In spite of many studies in amnesic patients, procedural learning has been rarely studied in control subjects especially with regard to effects of age and educational level.

The aim of this study was to establish in control subjects whether age, sex, education and classical results in explicit learning interact with implicit learning of visuomotor skills. We have subjected normal control subjects of various ages and PD patients to computer learning of different types of drawings. The handling of a mouse with a screen control appears to be a good example of implicit learning in naive subjects and this procedure could be useful in testing or rehabilitation.

\section{METHOD}

\section{Protocol}

We investigated the learning of mouse control while looking at the screen in six simple tests using Mac Paint (Macintosh). None of the subjects were experienced computer and mouse users. Using this procedure, we studied two kinds of learning: firstly, a general procedure of visuomotor coordination (mouse and screen) and secondly the specific procedures for each test. Tests were administered by the same observer, in a constant order with the same progression of difficulty during three sessions separated by 24 to $72 \mathrm{~h}$. Initially the experimenter briefly demonstrated how to move the mouse with the screen control. We measured the degree of learning using the time to complete each test for the three sessions and the percentage of improvement from the first session to the third one calculated as (t1-t3)/t 1$)$.

\section{Computerized tasks}

Blackboard. The screen is dark. The subject has to gum the black screen with the 'gum' tool. The movement is very simple and can be large since the gum may go off the screen.

Blots. Gumming dark blots with different forms and sizes distributed on the whole screen without gumming the background.

Crossing strokes. Crossing strokes distributed on the screen with the 'pencil' tool without doing a continuous draught. The movement is more accurate than the previous ones: the subject has to cross the stroke in the middle in a perpendicular way.

Maze. Performing a continuous route through three simple mazes from start to finish. The time to complete the task incorporates the time to solve the maze and the time to trace the route. Each of the three sessions used a different maze of equal difficulty (same length, removal and traps) to prevent a specific learning of the maze solution.

Figures. Drawing four simple figures (triangle, square, oval and circle) with the 'pencil' between a guide of two outlines.

Writing. Writing a non-word ('mul') in a forced outline.

\section{Neuropsychological tests}

We measured Performance IQ using the WAIS (Wechsler Adult Intelligence Scale).

Visual memory was assessed with part of the memory battery scale 144 of Signoret and Whiteley (1979) which analyzes learning and recall of non-verbal material (12 meaningless figures and a complex figure of 12 items).

Verbal memory was assessed with the recall of a story containing 22 items (the lion's fable of Barbizet); three parallel forms were used.

\section{POPULATION}

Tests were administered to 90 control subjects, aged between 16 and 75 years, (45 women, 45 men) split 
into five different age groups. They had different educational levels (elementary school in 30 cases, high school in 30 and university in 30 ). They had no neurological, visual, psychiatric or alcoholism histories. All were right-handed according to the criteria of Salmoso and Longoni, 1985.

Twenty-four PD patients aged between 40 and 75 years (mean age 65 years) were included (13 men, 11 women). Thirteen were of an elementary school level, six were of high school level and five were of an university education level. Mean duration of the disease was 51 months (between 6 months and 10 years). The stage of disease was assessed with the Hoehn and Yahr scale (1967): seven patients had the level 1, nine the level 2, and eight the level 3.

The clinical form of PD patients was recorded: seven patients had only tremor, (bilateral in all cases), four were akinetic and 13 had both akinesia and tremor. Drugs administered to the patients were taken into account: five patients had no treatment, two received a dopa-agonist treatment without levodopa and 17 a treatment including at least levodopa. We eliminated patients taking anti-cholinergic drugs.

\section{RESULTS}

\section{Control group}

The five aged groups were homogeneous. No control subject had to be excluded for poor performance. An analysis of variance was performed for all the results: WAIS PIQ ranged from 90 to 137 correlating with the educational level $(p=0.01)$; the mean score was the same for men and women $(p=0.55)$.

We measured the completion time for the tests and the percentage of improvement between the sessions. Although rate of learning may depend on initial performance, learning was similar in every test, and sufficient to shorten the completion time of 35 to $60 \%$
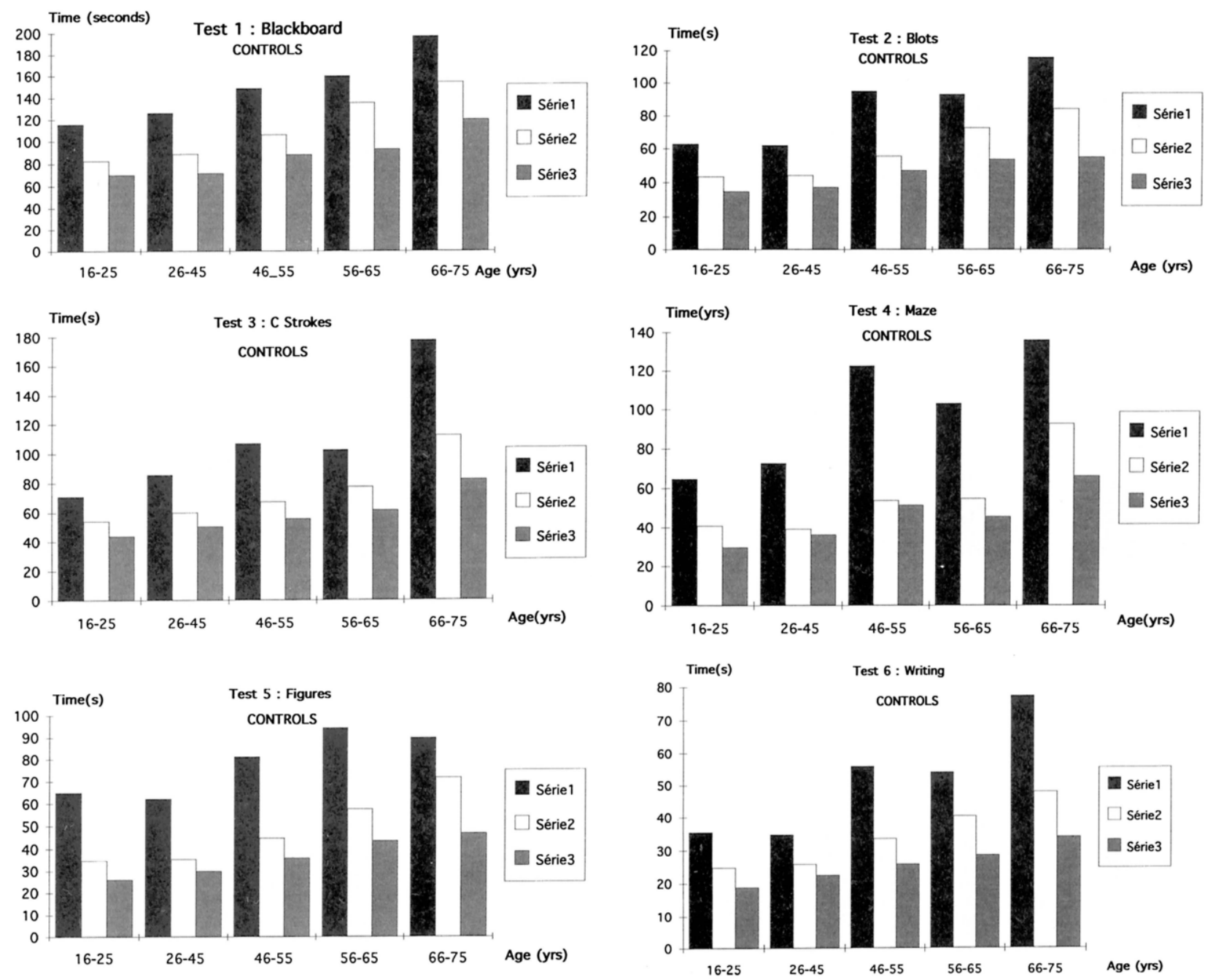

FIG. 1. Performance of control group in five age groups. Mean response times in six tests for three sessions. 
(Fig. 1). Performance in all tests improved in the same way. Improvement was greater for the two first sessions (15 to $56 \%$ ) than for the third one (4 to $35 \%$ ) suggesting a ceiling effect. The percentage of improvement from session 1 to 3 is considered as the procedural index. This index could be normal even with lower performance levels: the same percentage of improvement could occur with slow and fast performers. We used an analysis of variance (ANOVA) with five parameters: session, age, education, DIQ (WAIS) and sex. The influence of the session was always significant $(p=0.001)$ : all control subjects improved their performances in all tests (35 to 60\% according to the task and age). In contrast to the explicit memory measures (story recall), procedural results were independent of educational level or PIQ $(p>0.05)$. In some implicit tests the factor of sex was significant: men learned faster $(p<0.05)$ than women in crossing strokes, maze solving, and figure drawing. We observed a negative influence of aging in all six tests: subjects between 66 and 75 years of age performed twice as slowly as subjects aged between 16 and 25 years; but the percentage of improvement was very stable for the five different age groups (Fig. 1).

\section{PD patients group}

Results appear in Fig. 2. Statistical analysis was performed with a student's $t$-test (level of significance taken as $p<0.05)$ to compare the task completion times in control and PD patients groups (Table I).
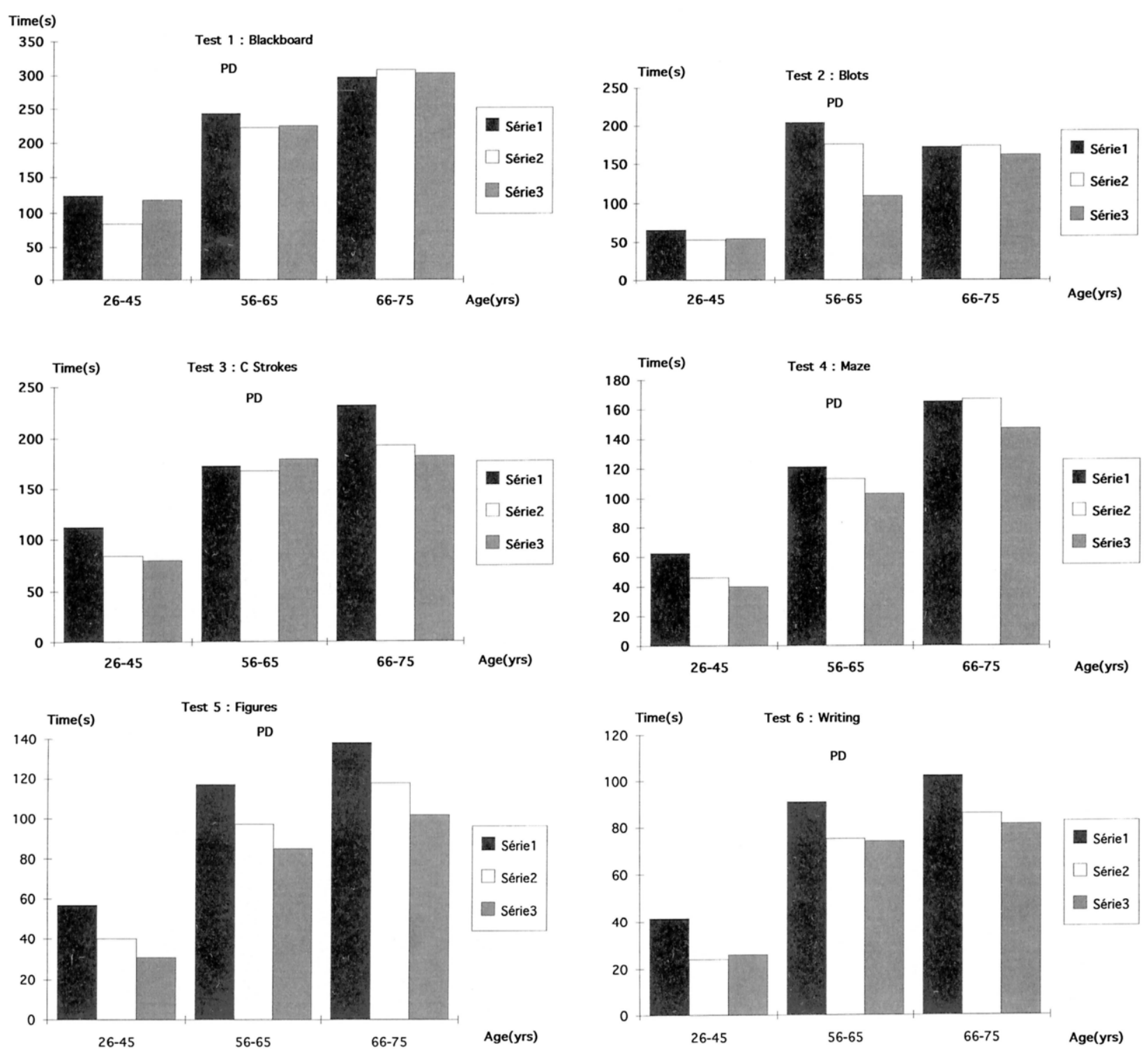

FIG. 2. Performance of three PD age group. Mean response times in six tests for three sessions. 
TABLE I. Results of Student's t-test in six tests. Comparison of time response in session 1 and 3 for PD patients and their controls.

\begin{tabular}{llllllll}
\hline Test & \multicolumn{2}{c}{$\begin{array}{c}p \text { values in session } \\
\text { 1 for patients aged: }\end{array}$} & & \multicolumn{2}{c}{$\begin{array}{c}p \text { values in session } \\
3 \text { for patients aged: }\end{array}$} \\
\cline { 2 - 5 } \cline { 6 - 8 } & $26-45$ & $56-65$ & $66-75$ & & $26-45$ & $56-65$ & $66-75$ \\
\hline 1 & 0.79 & 0.43 & 0.25 & & $0.04^{*}$ & 0.06 & $0.03^{*}$ \\
2 & 0.90 & $0.04^{*}$ & 0.17 & & 0.27 & $0.01^{*}$ & $0.02^{*}$ \\
3 & 0.53 & 0.15 & 0.39 & & 0.10 & $0.005^{*}$ & $0.03^{*}$ \\
4 & 0.70 & 0.64 & 0.52 & & 0.70 & $0.05^{*}$ & $0.05^{*}$ \\
5 & 0.85 & 0.62 & 0.29 & 0.90 & 0.17 & 0.10 \\
6 & 0.65 & 0.28 & 0.20 & 0.61 & 0.10 & 0.09 \\
\hline
\end{tabular}

TABLE II. Improvement for session 1 to 3 in two groups: control group and PD group.

\begin{tabular}{lccc}
\hline Test & \multicolumn{3}{c}{ Improvement (\%) between sessions 1 to 3 of: } \\
\cline { 2 - 4 } & $\begin{array}{c}\text { Control } \\
\text { subjects }(n=54)\end{array}$ & $\begin{array}{c}\text { PD patients } \\
(n=24)\end{array}$ & $\begin{array}{c}\text { Improvement } \\
\text { factor }\end{array}$ \\
\hline 1 & 41 & 5 & 8.0 \\
2 & 45 & 22 & 2.0 \\
3 & 45 & 17 & 2.6 \\
4 & 52 & 14 & 3.7 \\
5 & 51 & 31 & 1.6 \\
6 & 46 & 11 & 45 \\
\hline
\end{tabular}

TABLE III. Improvement for session 1 to 3 in two test (1 and 5) in PD group. Patients with Hoehn and Yahr scale for 1 to 3, patients with tremor or not, patients without treatment and patients with at least levodopa.

\begin{tabular}{lccccccc}
\hline \multirow{2}{*}{ Test } & \multicolumn{6}{c}{ Improvement (\%) between sessions 1 to 3 of patients with: } \\
\cline { 2 - 7 } & H\&Y1 & H\&Y2 & H\&Y3 & Tremor & No tremor & No treatment & Levodopa \\
\hline 1 & 10.3 & 10.9 & -3.8 & 1.5 & 4.9 & -16.9 & 7.2 \\
5 & 32.6 & 46.1 & 14.9 & 18.0 & 29.5 & 23.1 & 29.0 \\
\hline
\end{tabular}

$\mathrm{H} \& \mathrm{Y}=$ Hoehn and Yahr scale. Tremor, no tremor = clinical status.

Performances were similar between three age classes of PD patients and control subjects for the task completion time in the first session $(p<0.05)$ except for the second test in the 56-65 years of age group.

Significant differences appeared between all the patients and their controls in the first test of the third session. We observed significant differences in tests 2 , 3 and 4 only in 56-65 and 66-75 years of age groups in the third session $(p=0.05)$. The task completion times of each group of PD patients were longer than those of controls in the third session of the first test, and significantly longer in tests 2,3 and $4(p=0.05)$, for patients aged between 56 to 75 years. We compared percentage of learning in control and PD groups. The percentages of impairment are shown in Table II: the PD patients group improved between 1.6 and 4.5 times less than the 54 control group subjects matched for age.

In PD patients, we observed a 'first test' effect which affected the first test (the blackboard) of each session. The PD patients group was eight times more impaired than the control group. It could be attributed to initiate the general procedure of mousescreen. The correlations of procedural memory results with others paramaters have been evaluated in PD patients. Age and sex influenced the performance as in control subjects: younger patients were faster in all the tests; men were faster than women in crossing strokes and mazes $(p<0.05)$. Results were correlated to educational level: elementary school patients were slower and improved less than the two other groups $(p<0.05)$. In the neuropsychological battery 14 of the 23 patients had normal performance (PIQ higher than 90 , normal recall of the story, and normal performance in the visual memory battery 144); nine patients had a deficit in one or more of these tests. Patients with normal neuropsychological results had better initial computerised performances than those with deficit, but their procedural learning was always lower than the control group. Patients with the lowest motor scale of Hoehn and Yahr's scale (stage 1 and 2) performed faster $(p<0.05)$ and improved more than the more disabled patients (stage 3 ). On the other hand, patients with only tremor were initially faster $(p<0.05)$ but improved less than the other clinical groups. The influence of treatment could be studied in five de novo patients disabled from 6 months to 1 year: they had faster task completion times in the first session probably because of their low score of Hoehn and Yahr's scale; but they showed less improvement across the three sessions than the treated group which showed improvement of up to $30 \%$. Patients with levodopa were initially slower than the de novo ones. They improved more without obtaining better than $30 \%$ (35 to $60 \%$ for controls) (Table III). The most significant feature to distinguish PD patients and controls was the percentage of improvement. 


\section{DISCUSSION}

The aim of the study was to determine whether procedural learning could be demonstrated using a simple computerized visuomotor procedure over three sessions and differentiate between normal subjects and PD patients. In addition, we analyzed the performances according to age, sex, education and neuropsychological testing in three domains (PIQ, story recall and explicit visual memory). In our computerized procedure, improvements as measured by the task completion time were significant in all of the tests. Age was the only parameter which influenced response time in all sessions and in every test: young adults performed faster than older adults when classified into three age groups $(16-45,46-65,66-75)$ on all tests and at all three visits. But interestingly, procedural learning as measured by the improvement from the first to the third session was the same for all ages. Similarly to other skill-learning tasks which show preserved learning in old people (for example, the serial reaction-time task (Howard and Howard, 1989, 1992)) our tests do not involve complex processing. Movement and reaction times which are affected by aging obviously influence performance. As our measure of learning does not take into account the time of realization but the percentage of improvement across the sessions, our results are understandable.

No influence of educational level or practical intelligence (PIQ) may be found on skill learning in our tasks. Improvement with practice for these simple tasks does not require strategy or effortful cognitive processing usually correlated with educational level and PIQ. In comparison, the explicit memory tests were always dependent on these parameters and we observed the classical correlation between educational level, WAIS PIQ and explicit memory (story recall).

Significant sex effects on some tasks $(3,4,5)$ were detectable across three visits independently of age. Influence of sex on skill learning reflects significant differences for speed of completion. In the two simplest tests men and women performed similarly but speed differences emerged in the tests requiring greater accuracy. However, in all tests women learned as fast as men (that is, the percentage of improvement is the same). The influence of sex irrespective of age argues against an hormonal theory (Wright and Payne, 1985).

Our procedural battery was suitable for PD patients as it has been used in some previous studies with others tools (Frith et al., 1986; Pillon et al., 1986; Saint-Cyr et al., 1988; Brown and Marsden, 1990). We observed a clear dissociation between implicit and explicit memory: 14 PD patients had normal results for explicit verbal and visual tasks, but a clear deficit in procedural learning. Thus, the procedural impairment seems to be one of the first cognitive deficits in PD patients (Lees and Smith, 1983).

Paradoxically the difficulties in procedural learning seem greater for patients with tremor alone but this result must be examined with care because of the small number of patients (seven). In the literature patients with predominant tremor performed better in terms of explicit memory and other types of neuropsychological tests (Lavernhe et al., 1989; Guillard et al., 1991). Robbins et al. (1994) used a computerized version of the Tower of London planning task and demonstrated that patients with more severe clinical disability are also impaired in the accuracy of solutions, as indexed by the minimum moves measure and in subsequent thinking time.

We observed an effect of dopatherapy since treated patients improved better than de novo patients in spite of slower response times in the first session. The rate of learning may depend on the initial performance. But even with dopatherapy PD patients improved two or three times less than the control group. In the literature the influence of treatment on cognitive performances has been demonstrated for perceptive or motor tasks and for reaction times (Girotti et al., 1986; Pillon et al., 1989). Newman et al. (1984) showed that in elderly subjects levodopa selectively facilitated effortful, as opposed to automatic, memory processes. Cooper et al. (1992) concluded that dopaminergic and anticholinergic treatments both led to improvement in motor control but their effects upon cognitive performance dissociated. Anticholinergic drugs produced impairment in immediate registration of information whilst dopaminergic therapy produced improvement on tasks dependent on working memory and cognitive sequencing. The cognitive impairment in PD is of multifactorial origin. In our tests, levodopa seems to influence procedural learning but not the rapidity of the first session and this data is confusing. If levodopa influences the motor plan before movement (Taylor et al., 1986; Brown and Marsden, 1990) the effect must appear following the first trial. It is possible that the specific role of levodopa in procedural learning, appears only during training (El Awar et al., 1987; Saint-Cyr et al., 1988; Heindel et al., 1989; Fimm et al., 1990). In the serial reaction time task Pascual-Leone (1993) showed that normal volunteers and patients with PD acquired procedural knowledge of the sequence, as measured by a reduction in the response time and a 
decrease in error rates. Antiparkinsonian medication did not significantly affect these findings. However, at longer sequence lengths, patients with PD showed significantly less performance improvement that normal volunteers, particularly in the untreated state. The study of parkinsonian patients who had never been treated showed that their reaction times were better than PD patients with levodopa treatment responses. In the earliest clinical stages of disease, we observed, as suggested Cooper et al. (1992), two sets of dissociable processes: one involving motor control and producing psychomotor retardation and the second serving cognition and impairing working memory and attention.

The correlations between procedural memory and general variables vary according to the groups: influences of age and sex were the same in the control and PD patient groups. The educational level and PIQ results were correlated with procedural performance only in the PD patients; these factors could play a role of substitution or help for disabled patients while they are not necessary in normal people. Many debates are devoted to the role of explicit strategy in procedural learning. Even if our procedural testing seems very implicit without requiring a conscious recollection from a previous experiment, we suppose that patients could compensate for the difficulties of implicit memory with explicit strategies.

We observed a negative 'first session' effect in the PD patients only. Patients are slower in the first test of each session as if they have difficulty in initiating the procedure 'mouse-screen' even for the first very simple test of gumming a blackboard. For this first task, PD patients improved eight times less than the control group. The task completion times of patients were always longer than those of controls in third session of the first test. PD patients had difficulty in initiating a motor plan, as Brown and Marsden (1991) suggested. They have difficulties in the automatic execution of learned motor plans or at least in their initiation. Our results confirmed the hypothesis of Saint-Cyr et al. (1988): success in procedural tasks for PD patients depends on the capacity to initiate the response and not the capacity to develop an accurate strategy.

Many questions still remain unanswered, especially the role of motor slowness in PD patients and the possible intervention of explicit strategy in these tasks. Other kinds of implicit memory have to be studied to differentiate performances of different pathologies of the basal ganglia and sub-types of PD patients (Bondi and Kaszniak, 1991). Different kinds of tasks (more or less effortful or cognitive) must be used. In our battery the sensory-motor aspect is dominant even in the maze tracing and we did not observe poor results for the most difficult tests. The main criticism could be related to the role of motor slowness of our PD patients since the tasks are heavily dependent on motor coordination but two facts argue against this exclusive role. First, the performance during the first session was nearly the same in the PD patients as in the control group and the difference of task completion time is not significant with a Student's $t$-test $(p>0.05)$. Second, the procedural learning deficit appeared in all patients, even at onset of disease for those with slight akinesia according to Hoehn and Yahr's scale. It may be that PD patients fail to improve across trials because they have a motor impairment which does not perturb the first trial but does not allow the procedural gain to be expressed. The fact that some patients have a normal rate of learning, that others have different learning rates across the sessions, that the dopatherapy could improve the procedural learning without modifying the first session, and that we observed a strong first session effect argues against this simple motor interpretation. Execution times of PD patients aged between 56 and 75 years were significantly longer in test 2,3 and $4(p=0.05)$. They seemed to improve along the different tests that once more argues against this simple motor interpretation.

Others procedural tasks in literature as the mirror reading task are so sensitive even if they do not implicate limbs movements.

If we admit that simple motor or attentional deficits could not explain the results we must also analyze a possible frontal syndrome with difficulties to initiate a motor program requiring a visuospatial treatment and impairment for sequencing and setshifting. The first test effect in each session reveals a difficulty in initiating the program, but the normal response times in the other tests of the first session argues against a deficit in sequencing or shifting or a fatigue effect. These factors could be critical to gain time across the sessions and we cannot differentiate between the role of a decreased specific motor memory dependent on nigrostriatal structure and that of a frontal subcortical syndrome. Whatever the mechanism, the procedural approach appears very promising to evaluate $\mathrm{PD}$ patients and the influence of aging on this sub-type of memory.

\section{REFERENCES}

Bondi MW and Kaszniak WA (1991) Implicit and explicit memory in Alzheimer's disease and Parkinson's disease. Journal of clinical and Experimental neuropsychology, 13, 339-3358. 
Brooks DN and Beddeley AD (1976) What can amnesic patients learn? Neuropsychologia, 14, 111-122.

Brown RG and Marsden CD (1990) Cognitive function in Parkinson's disease: from description to theory. Trends in Neuroscience, 13, 21-29.

Cohen NJ and Squire LR (1980) Preserved learning and retention of pattern analysing skill in amnesia: Dissociation of knowing how and knowing that. Science, 210, 207-210.

Cohen NJ (1984) Preserved learning capacity in amnesia: evidence for multiple memory systems. In: Neuropsychology of Memory, (Eds Squire and Butters) pp. 83-103. Guilford Press, New York.

Cooper JA, Sagar SM, Doherty SM, Jordan N, Tidswell P and Sullivan EV (1992) Different effects of dopaminergic and anticholinergic therapies on cognitive and motor function in Parkinson's disease. Brain, 115, 1701-1725.

Corkin S (1968) Acquisition of motor skill after bilateral medial temporal excision. Neuropsychologia, 6, 255-265.

El-Awar M, Becker JT, Hammond KM, Nebes RD and Boller F (1987) Learning deficit in Parkinson's disease. Comparison with Alzheimer's disease and normal aging. Archives of Neurology, 44, 180-184.

Fimm B, Zimmermann P, Sprengelmeyer R and Wallesch CW (1990) Reaction and movement times in simple and choice reactions in untreated and treated Parkinson's disease. Poster, VII European Workshop on Cognitive Neuropsychology, Bressanone.

Frith CD, Bloxham CA and Carpenter KN (1986) Impairments in the learning and performance of a new manual skill in patients with Parkinson's disease. Journal of Neurology, Neurosurgery and Psychiatry, 49, 661-668.

Girotti F, Carella F, Grassi MP, Soliveri P, Marano R and Caraceni T (1986) Motor and cognitive performances of Parkinsonian patients in the on and off phases of the disease. Journal of Neurology, Neurosurgery and Psychiatry, 49, 657-660.

Glisky EL, Schacter DL and Tulving E (1986) Computer learning by memory-impaired patients: acquisition and retention of complex knowledge. Neuropsychologia, 24, 313-328.

Glisky EL and Schacter DL (1989) Extending the limits of complex learning in organic amnesia: computer training in a vocational domain. Neuropsychologia, 27, 107-120.

Harrington DL and Haaland KY (1991) Sequencing in Parkinson's disease. Abnormalities in programming and controlling movement. Brain, 114, 99-115.

Heindel WC, Salmon D, Shults C, Walicke PA and Butters N (1989) Neuropsychological evidence for multiple implicit memory systems: a comparison of Alzheimer's, Huntington's and Parkinson's disease patients. Journal of Neuroscience, 9, 582-587.

Hoehn MM and Yahr MD (1967) Parkinsonism: onset, progression, and mortality. Neurology, 17, 427-442.

Howard DV and Howard JH (1989) Age differences in learning serial patterns: direct versus indirect measures. Psychology and Aging, 4, 357-364.

Knopman DS and Nissen MJ (1987) Implicit learning in patients with probable Alzehimer's disease. Neurology, 37, 784-788.

Lavernhe G, Pollak P, Brenier F, Gaio JM, Hommel M, Pellat J and Perret J (1989) Maladie d'Alzheimer et maladie de Parkinson. Différenciation neuropsychologique. Revue Neurologique, 145, 24-30.

Lees AJ and Smith E (1983) Cognitive deficits in the early stages of Parkinson's disease. Brain, 106, 257-270.

Martone M, Butters N, Payne M, Becker JT and Sax DS (1984) Dissociations between skill learning and verbal recognition in amnesia and dementia. Archives of Neurology, 41, 965-970.

Milner B, Corkin S and Teuber HL (1968) Further analysis of the hippocampal amnesic syndrome: 14-year followup study of H.M. Neuropsychologia, 6, 215-234.

Morris RG, Downes JJ, Sahakian BJ, Evenden JL, Heald A and Robbins TW (1988) Planning and spatial working memory in Parkinson's disease. Journal of Neurology, Neurosurgery and Psychiatry, 51, 757-766.

Newman RP, Weingertner H, Smallberg SA and Calne DB (1984) Effortful and automatic memory: effects of dopamine. Neurology, 34, 805-807.

Pascual-Leone A, Grafman J, Clark K, Stewart M, Massaquoi S, Lou JS and Hallett M (1993) Procedural learning in Parkinson's disease and cerebellar degeneration. Annals of Neurology, 34, 594-602.

Parkin AJ (1982) Residual learning capability in organic amnesia. Cortex, 18, 417-440.

Pillon B, Dubois B, Lhermitte F and Agid Y (1986) Heterogeneity of cognitive impairment in progressive supranuclear palsy, Parkinson's disease and Alzheimer's disease. Neurology, 36, 1179-1185.

Pillon B, Dubois B, Cusimano G, Bonnet AM, Lhermitte F and Agid Y (1989) Does cognitive impairment in Parkinson's disease result from non-dopaminergic lesions? Journal of Neurology, Neurosurgery and Psychiatry, 52, 201-206.

Robbins TW, James M, Owen AM, Lange KW, Lees AJ, Leigh PN, Marsden CD, Quinn NP and Summers BA (1994) Journal of Neurology, Neurosurgery and Psychiatry, 57, 79-88.

Saint-Cyr A, Taylor AE and Lang AE (1988) Procedural learning and neostriatal dysfunction in man. Brain, 111, 941-959.

Salmaso D and Longoni AM (1985) Problems in the assessment of hand preference. Cortex, 21, 533-549.

Schacter DL (1987) Implicit memory: history and current status. Journal of Experimental Psychology: Learning, Memory and Cognition, 13, 501-518.

Serdaru M and Lhermitte F (1981) Etude des syndromes amnésiques par la méthode du conditionnement palpébral et de la réaction de sursaut et d'orientation. Revue Neurologique, 1, 39-47.

Signoret JL and Whiteley A (1979) Memory battery scale. International Neuropsychological Society Bulletin, 2, 26.

Squire LR and Cohen NJ (1984) Human memory and amnesia. In: Neurobiology of Learning and Memory (Eds McGaugh, G Lynch and N Weinberger), Guilford Press, New York.

Tulving E (1985) How many memory systems are there? American Psychologist, 40, 385-398.

Warrington EK and Weiskrantz L (1982) Amnesia: a disconnection syndrome? Neuropsychologia, 20, 233-248.

Wright BM and Payne RB (1985) Effects of aging on sex differences in psychomotor reminiscence and tracking proficiency. Journal of Gerontology, 179-184. 


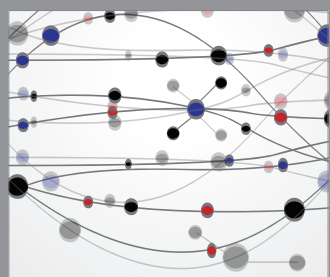

The Scientific World Journal
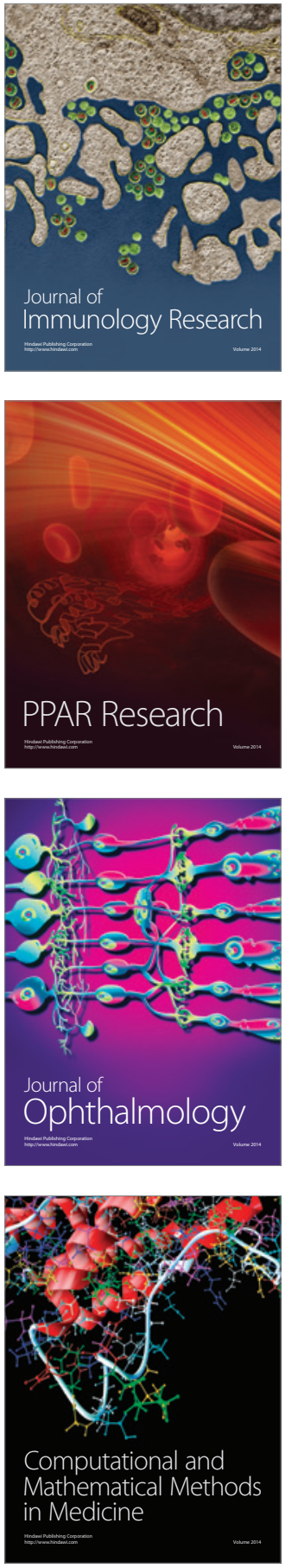

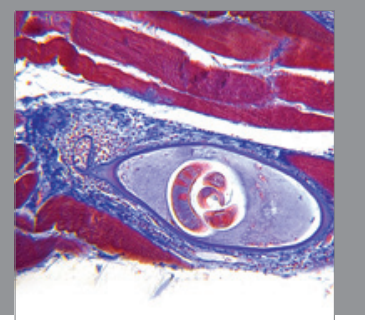

Gastroenterology

Research and Practice
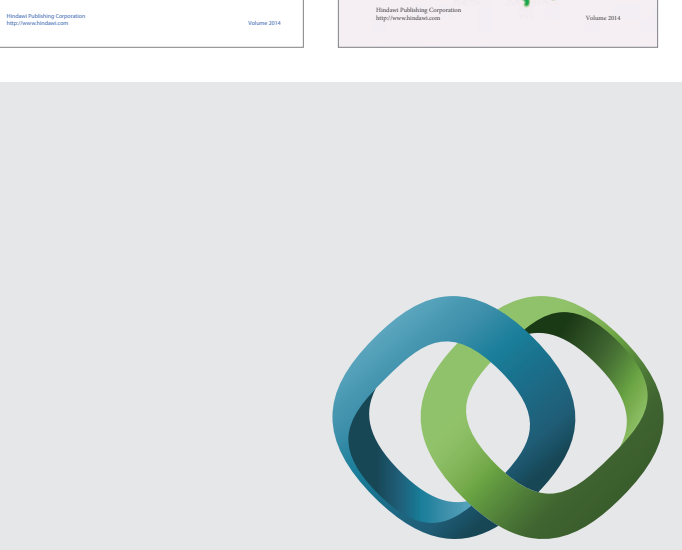

\section{Hindawi}

Submit your manuscripts at

http://www.hindawi.com
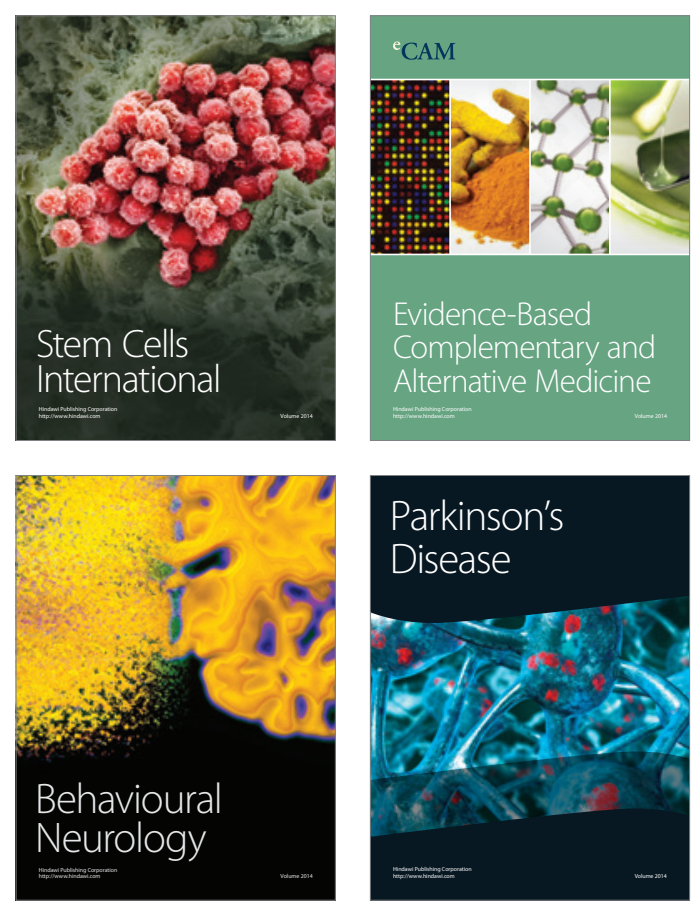

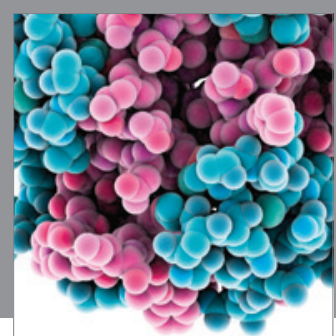

Journal of
Diabetes Research

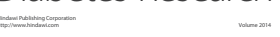

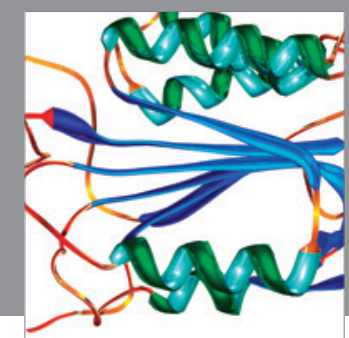

Disease Markers
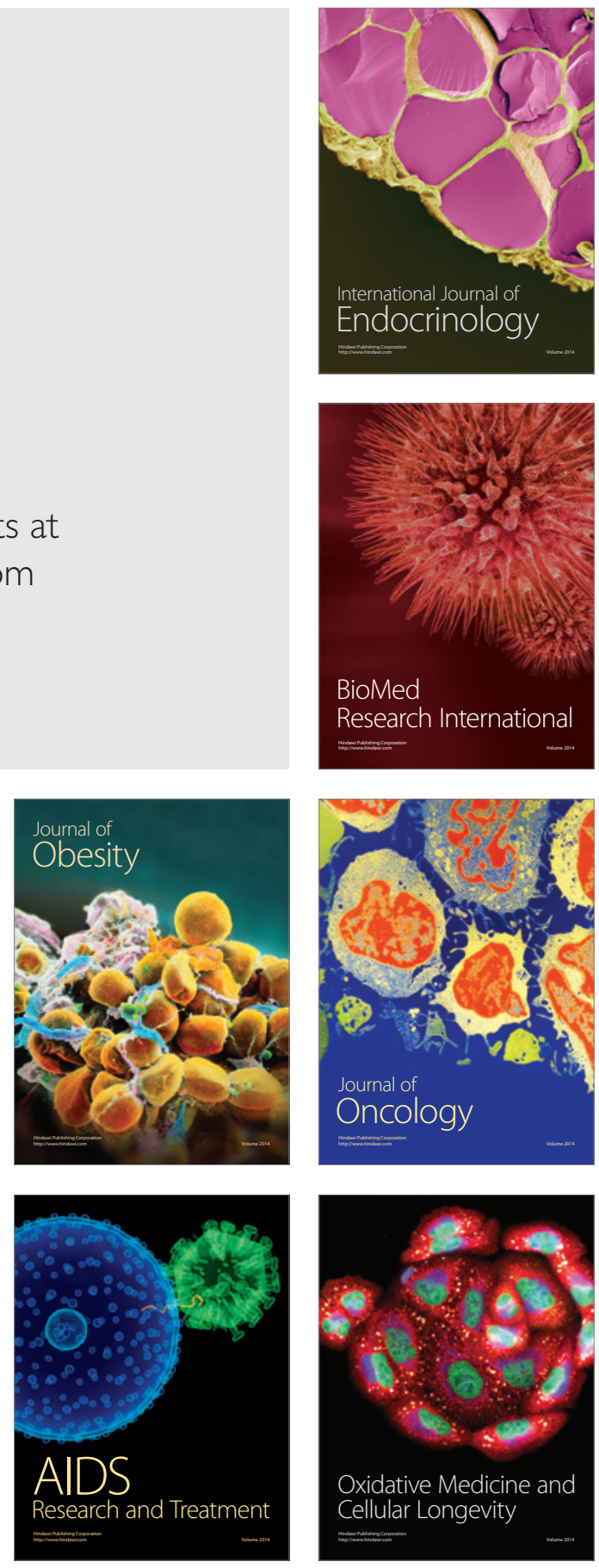